\title{
Social Capital and Knowledge Integration in Digitally Enabled Teams
}

\author{
Lionel P. Robert, Jr. \\ Sam M. Walton College of Business, University of Arkansas, Fayetteville, Arkansas 72701, \\ lrobert@walton.uark.edu \\ Alan R. Dennis \\ Operations and Decision Technologies Department, Kelley School of Business, Indiana University, \\ Bloomington, Indiana 47405, ardennis@indiana.edu \\ Manju K. Ahuja \\ Computer Information Systems Department, College of Business, University of Louisville, \\ Louisville, Kentucky 40292, manju.ahuja@louisville.edu
}

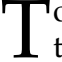
o understand the impact of social capital on knowledge integration and performance within digitally enabled teams, we studied 46 teams who had a history and a future working together. All three dimensions of their social capital (structural, relational, and cognitive) were measured prior to the team performing two tasks in a controlled setting, one face-to-face and the other through a lean digital network. Structural and cognitive capital were more important to knowledge integration when teams communicated through lean digital networks than when they communicated face-to-face; relational capital directly impacted knowledge integration equally, regardless of the communication media used by the team. Knowledge integration, in turn, impacted team decision quality, suggesting that social capital influences team performance in part by increasing a team's ability to integrate knowledge. These results suggest that team history may be necessary but not sufficient for teams to overcome the problems with the use of lean digital networks as a communication environment. However, team history may present a window of opportunity for social capital to develop, which in turn allows teams to perform just as well as in either communication environment.
\end{abstract}

Key words: social capital; social network analysis; network analysis; computer-mediated communication; collaboration; virtual teams; lab experiments; knowledge sharing; information sharing

History: Robert Kraut, Senior Editor. This paper was received on July 15, 2006, and was with the authors 6 months for 3 revisions.

\section{Introduction}

Organizations use teams to make decisions because teams are believed to provide access to larger pools of expertise than any individual manager acting alone (Deeter-Schmelz and Ramsey 2003, Dennis 1996, Stasser and Titus 1985). This belief assumes that team members will exchange and use (i.e., "integrate") all relevant knowledge during discussions. Unfortunately, research has shown that this knowledge integration is often inadequate, which often leads to poor decisions (Dennis 1996, Stasser and Stewart 1992, Hollingshead 1996, Straus 1996). Although knowledge integration is not without problems in faceto-face teams, it is particularly difficult when team members communicate primarily through "lean" dig- ital networks (Heninger et al. 2006, Graetz et al. 1998, Dennis 1996, Straus and McGrath 1994). Thus, a team's performance may not be hindered by its individual members' lack of ability but instead by the team's failure to integrate all available information and knowledge (Reus and Liu 2004).

In teams, knowledge is inherently rooted in individual members' experience and expertise (Choo 1998). This personal nature of knowledge requires social interactions between team members before private individual knowledge can be converted into public team information (Inkpen and Tsang 2005). As a result, we believe that social capital-the set of resources embedded within the relationships among actors within a network-will influence knowledge 
integration in teams (Nahapiet and Ghoshal 1998, Inkpen and Tsang 2005, Oh et al. 2004). We posit that three primary dimensions of social capital (structural, relational, cognitive) impact knowledge integration which, in turn, influences performance. In addition, we propose that all three dimensions will be more important for knowledge integration when teams communicate primarily through lean digital networks, as compared to richer face-to-face media.

Most teams today are digitally enabled, meaning that they use traditional face-to-face communication, as well as a host of other media, including phone, video, and lean digital networks. Digitally enabled teams are hybrid teams; their members do not work in a fixed space and time but instead work at various points on the space-time continuum on different occasions-sometimes face-to-face, sometimes synchronously at different places, and sometimes asynchronously. In this study, we focus on teams in which members have known each other in the past (and have had an opportunity to develop social capital) and who work face-to-face and through lean digital networks.

We report on a laboratory study of 46 digitally enabled teams that interacted for 6 to 8 weeks prior to the experiment and expected to work together for another 3 to 4 weeks. Thus, when the experiment was performed, the teams had a history and an expectation of a future together. The results show that relational capital significantly affected knowledge integration whether teams worked face-to-face or via a lean digital network. Structural and cognitive capital had a greater impact on knowledge integration when teams communicated through lean digital networks than in face-to-face environments, reducing some of the negative effects of lean digital media. Finally, knowledge integration was an important predictor of team performance. We believe this study makes two key contributions. First, it shows that social capital reduces the negative effect of lean digital networks by improving the knowledge integration. Second, it offers an alternate explanation, social capital, as to why teams with a history may be able to perform as well in either communication environment (cf. van der Kleij et al. 2005, Alge et al. 2003, Mennecke and Valacich 1998, Hollingshead et al. 1993, McGrath and Hollingshead 1993).

\section{Theoretical Background and Research Model}

In this paper, we propose that three dimensions of social capital (structural, relational, and cognitive) influence a team's ability to integrate knowledge, which in turn improves team decision making. We further posit that while communication thought lean digital networks hinders knowledge integration (as compared to face-to-face interaction), teams with strong social capital are better able to overcome the limitations of the lean digital environment to integrate knowledge. Figure 1 provides a summary of these arguments, which are elaborated later.

\section{Knowledge Integration and Team Performance}

There are many definitions for knowledge integration. Drawing on Alavi and Tiwana (2002) and Patrashkova-Volzdoska et al. (2003), we define knowledge integration as the "synthesis" of individual team members' information and expertise through "social interactions." Management scholars have highlighted the importance of knowledge integration in organizational decision making: "the primary role of the firm ... is the integration of knowledge" (Grant 1996b, p. 375) and have noted that the ability to integrate the knowledge of individuals is the "cornerstone" of dynamic capabilities (Eisenhardt and Martin 2000). Three key mechanisms for knowledge integration are directives, organizational routines, and teams (Grant 1996b). In situations of high uncertainty and complexity, directives and routines may not enable successful knowledge integration, so teams are often formed for such situations (Grant 1996b).

The most important resource that teams have is their members' knowledge, and their most important capability is the ability to integrate this knowledge (Reus and Liu 2004, Grant 1996a). The success of knowledge-intensive teams depends on their ability to integrate the knowledge held by each team member-that is, their ability to enable each member to contribute his or her unique information and knowledge to the team discussion and the thoughtful consideration of that unique knowledge and information by other team members (Dennis 1996, Reus and Liu 2004). In high-performing teams, team members not only combine present knowledge but also use 
Figure 1 Research Model

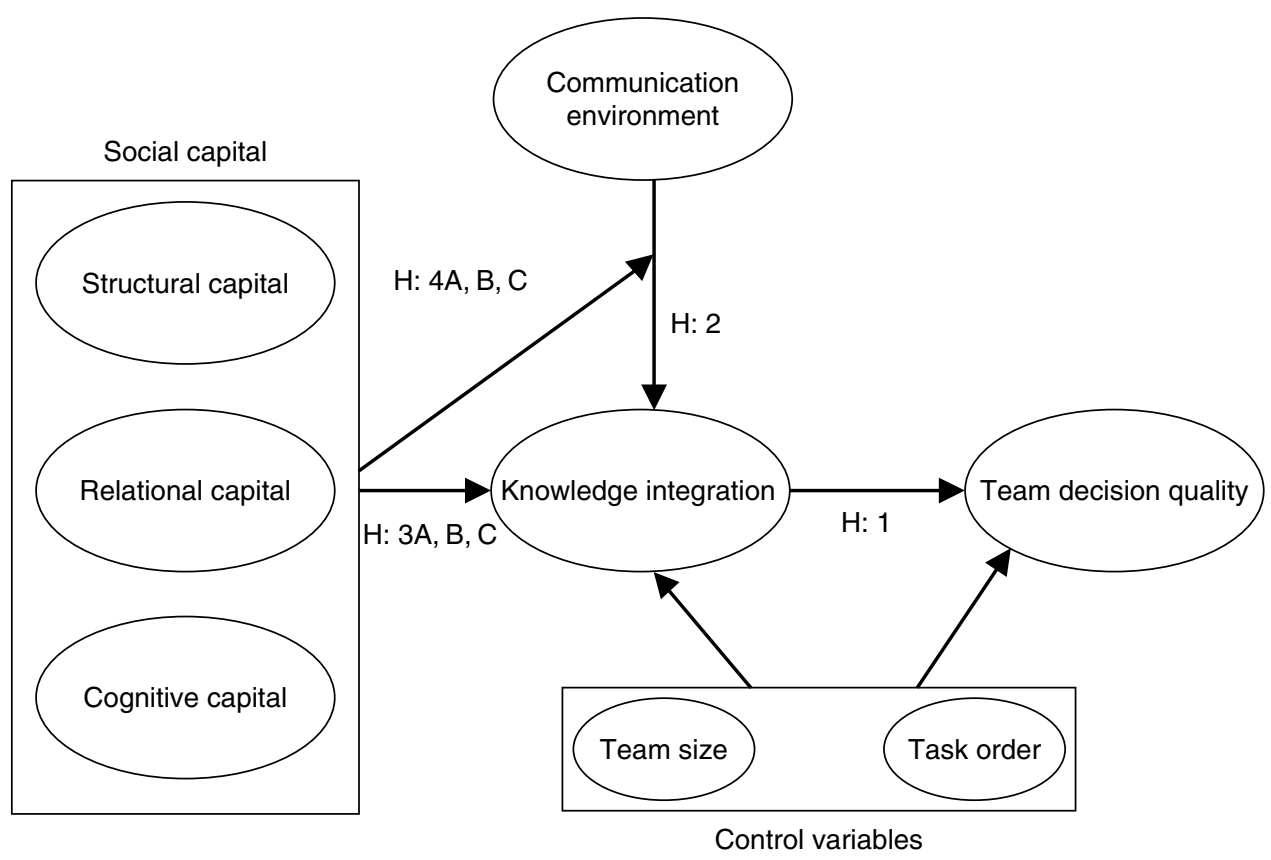

it to generate new knowledge that forms the foundation of imaginative thinking and creative problem solving (Reus and Liu 2004). Despite the importance of knowledge integration to performance, there is an abundance of empirical evidence that teams are generally poor at knowledge integration, whether they work face-to-face (e.g., Stasser and Titus 1985, Stasser and Stewart 1992) or via lean digital networks (e.g., Heninger et al. 2006, Alavi and Tiwana 2002, Graetz et al. 1998, Dennis 1996, Straus and McGrath 1994).

Knowledge integration is not a deterministic process of mechanically assembling discrete pieces of information but is instead a "dance" of communication and exchange that can evoke new "associations, connections, and hunches [that can lead to] new meaning and insights" (Newell et al. 2004, p. 45). The knowledge integration process enables teams to piece together bits of information, based on their relationships. This process requires both information sharing and information utilization (Reus and Liu 2004, Dennis 1996, Gruenfeld and Hollingshead 1993), as well as coordination (Lin and Chen 2006, Barki and Pinsonneault 2005, Grant 1996a, b). Formal intervention techniques can improve knowledge integration (Okhuysen and Eisenhardt 2002, Hilmer and Dennis
2001, Dennis et al. 1998, Stasser and Stewart 1992, Stasser and Titus 1985).

The relationship between knowledge integration and decision quality is based on the assumption that no one team member has all of the relevant knowledge to obtain the best solution for performing the task. Team members need not only to share and use each other's information but also to understand the relationship among the pieces of information to reach a more informed decision (Tiwana and McLean 2005). The result of the knowledge integration process will yield a comprehensive understanding of the problem and the viable solutions. Knowledge integration is particularly important when teams perform highly interdependent tasks (Okhuysen and Eisenhardt 2002).

Past research has found a positive association between knowledge integration and performance (Ickes and Gonzalez 1994). For example, knowledge integration within teams has been found to reduce software defects (Tiwana 2004) and increase the performance of product innovation teams (Lin and Chen 2006). Other studies have found that information sharing and processing within teams, both necessary for knowledge integration, were positively associated with team productivity and performance 
(Campion et al. 1993, Dennis 1996, Huang and Newell 2003). Therefore, we offer Hypothesis 1.

Hypothesis 1 (H1). Knowledge integration is positively related to team decision quality.

\section{Digital Networks for Communication}

The use of lean digital networks as a communication environment has proliferated throughout society. Synchronous text messaging (STM) is one of the most popular communication tools in use today, and its use continues to grow. Early on, STM was used primarily by teens to communicate with their friends but reports show it is now widely adopted as a corporate workplace tool. In 2002, $84 \%$ of organizations had some type of STM service; the number is now estimated to be more than $90 \%$ (Hu 2003). A study by Pew Internet \& American Life found that 53 million American adults use STM; $21 \%$ of those (11 million) use it in their workplace to increase productivity and interoffice cooperation (Shiu and Lenhart 2004). The importance of STM was highlighted when members from Lehman Brothers, J. P. Morgan Chase, Merrill Lynch, Morgan Stanley Dean Witter, UBS, and Deutsche Bank convened the first Instant Messaging Standard Board (IMSB) to demand new interoperability standards for STM (Olsen 2002). To quote Forrester Research analyst Charles Golvin (Hu 2003):

The sea change is that enterprises are realizing that this [STM] is actually a productivity tool, a real-time business and connectivity tool,... The mind shift is instead of trying to block this, let's take advantage of it to make us more nimble and responsive. (http://news. com.com/Message+in+a+bottleneck/2009-1033_3-992348. html)

Fortunately, as a research community, we have a long tradition of rich research studying the use of STM. In particular, many studies have examined the use of STM by decision-making groups (Straus and McGrath 1994, Hollingshead et al. 1993, Graetz et al. 1998, Baltes et al. 2002, Dennis and Wixom 2002). Kiesler et al. (1984), in one of the earliest studies on team STM use, discovered that teams who used STM differ from face-to-face teams in participation, decisions, and interactions. Since then, many studies have examined the impacts of anonymity, production blocking, and the use of lean digital networks on such outcomes as satisfaction, decision quality, idea generation, and time (Baltes et al. 2002, Dennis and Wixom 2002, Dennis et al. 2001, Burke and Chidambaram 1999, Dennis and Kinney 1998, Galegher and Kraut 1994, Kiesler et al. 1985, Hiltz and Johnson 1990, Mennecke and Valacich 1998, Siegel et al. 1986, Straus and McGrath 1994).

\section{Communication and Knowledge Integration}

Communication through lean digital networks is more restrictive than face-to-face communication. The impact of communication through lean digital networks can be viewed through three theoretical lenses: individual, interpersonal, and team. First, at the individual level, communication through lean digital networks reduces the ability of an individual to process information by increasing his or her cognitive load (Straus 1996, Graetz et al. 1998, Robert and Dennis 2005, Heninger et al. 2006). Straus (1996) introduced "attention blocking" as an explanation for why team members who communicated using STM had difficulty integrating knowledge. Team members must process other members' information and, at the same time, think about and type their own responses. When that occurs, team members are less likely to process all the relevant information when making a decision (Heninger et al. 2006).

At the interpersonal level (e.g., in communication between two individuals), the use of lean digital networks may make it harder to convey meaning "above and beyond the literal intent" (Graetz et al. 1998, p. 715) for two reasons. First, lean digital networks are less able to transmit verbal tone and nonverbal cues, such as emotional or attitudinal information (Daft and Lengel 1984, Daft and Lengel 1986, Kiesler et al. 1984, Sproull and Kiesler 1986, Graetz et al. 1998). Second, lean digital networks are less able to provide concurrent feedback between the receiver and sender (Daft and Lengel 1984, Daft and Lengel 1986, Kiesler et al. 1984, Sproull and Kiesler 1986, Graetz et al. 1998, Dennis and Wixom 2002). Reduction of cues and feedback can decrease shared understanding (Dennis and Wixom 2002, Straus and McGrath 1994, Siegel et al. 1986).

The third barrier occurs at the team level. Team coordination and control through lean digital networks is more difficult (Kiesler et al. 1984). Digitally enabled team members are sometimes separated by 
space and lack traditional monitoring mechanisms for maintaining a sense of social control necessary for team coordination (Jarvenpaa et al. 1998, Piccoli and Ives 2003). This problem can be further compounded by parallelism. Parallelism enables all team members to communicate at will, which presents several problems. First, use of STM increases the likelihood of simultaneous multiple conversations, conversations in which some team members are discussing one topic while others have moved on to discuss a new topic, which often results in poor communication and integration of the communication content (Strømsø et al. 2007). In face-to-face discussions, simultaneous multiple conversations can be recognized and rectified; however, when team members communicate through digital networks, simultaneous multiple conversations are more common and often go unchallenged (Dennis and Valacich 1994). Team members can more easily ignore information in these parallel conversations (Dennis 1996). As a result, the use of lean digital networks should reduce knowledge integration.

Hypothesis 2 (H2). Communication through lean digital networks reduces knowledge integration.

\section{Three Dimensions of Social Capital in Teams}

Social capital has been defined as "resources embedded in social networks accessed and used by actors for action" (Lin 2001, p. 25). Consistent with Nahapiet and Ghoshal (1998), we adopt the view that teams are small networks in which their actors exchange resources and knowledge (Oh et al. 2006) to accomplish the task. These networks exhibit structure (pattern of exchange) and intensity (frequency of exchange) (Ahuja and Carley 1999, Sparrowe et al. 2001, Reagans and Zuckerman 2001, Rulke and Galaskiewicz 2000). The ease of knowledge exchange between team members increases with the level of shared understanding about the team, task, and technology (Marks et al. 2002, Cannon-Bowers et al. 1993).

There is a plethora of research on social capital in organizations, but there is a lack of agreement about what comprises social capital (Adler and Kwon 2002). We adopt one of the most commonly used conceptualizations of social capital. Nahapiet and Ghoshal (1998) argue that social capital has three dimensions: structural, relational, and cognitive. The structural dimension relates to the ties among actors and reflects the potential resources available to an actor or a team (i.e., "who knows whom"). The relational dimension refers to the nature of social relations developed through a history of interaction among the team members. The cognitive dimension refers to shared representations, interpretations, systems, and language. This multi-dimensional view of social capital provides a valuable theoretical lens because each dimension "facilitates the creation and exchange of knowledge" (Nahapiet and Ghoshal 1998, p. 243). In later sections of this paper, we examine "how" and "why" social capital impacts knowledge integration.

\section{Structural Capital and Knowledge Integration}

Structural capital reflects the overall pattern of interactions among team members (Nahapiet and Ghoshal 1998, Wasko and Faraj 2005) and is reflected in a team's social network structure. A team's social network structure, "the quality and patterns of relationships existing among group members" (Rulke and Galaskiewicz 2000, p. 613), not only defines the links that bind individuals together but also provides the potential channels for the transmission and use of information (Nahapiet and Ghoshal 1998). Social interactions through the network ties are the mechanisms by which teams exchange information to integrate knowledge successfully (Patrashkova-Volzdoska et al. 2003) and are directly related to performance for knowledge integration tasks (Baldwin et al. 1997).

Although there are many ways to conceptualize and measure structural capital, we view it as a function of intensity and decentralization (Rulke and Galaskiewicz 2000, Zack and McKenney 1995). Intensity represents the extent to which teams utilize their available ties to interact. In essence, the intensity of a team's network represents the amount of social interactions among team members (unlike density, which represents the number of ties used within a network) (Rulke and Galaskiewicz 2000). Interactions among individuals have been shown to be an important determinant of knowledge sharing and use in traditional (Brass et al. 2004, Borgatti and Cross 2003), as well as digital, groups (Ahuja et al. 2003). Teams that are high in network intensity will exhibit greater interactions among team members.

Decentralization describes a distributed pattern of these social interactions (Rulke and Galaskiewicz 
2000). The structure of social interactions can both constrain and enable access to information (Sparrowe et al. 2001, Ibarra 1993). Teams with more decentralized networks have a habit of exchanging information among more team members. As a result, teams with decentralized networks will not have a history of one or two members dominating discussions, as seen in centralized networks, where one or two team members dominate team discussions and most information is funneled through them.

The impact of a team's social structure varies according to the nature of the task. Highly centralized structures are more efficient for simple information tasks that are low on task interdependency (Bavelas 1950, Shaw 1964). Centralized networks are preferred when one or two team members have all of the information needed to find an optimal team solution (Bavelas 1950, Shaw 1964). However, there are at least three disadvantages to centralized networks when teams are performing a highly interdependent task. One, centralized networks are ineffective when the task requires the use of unique information from all of the team members (Shaw 1964, Rulke and Galaskiewicz 2000). Second, one or two team members cannot always effectively process all of the information needed for the entire group or team (Ahuja and Carley 1999). Three, multiple perspectives can provide new insights to solving problems, which is lost when some team members do not actively participate in team discussions (De Dreu and West 2001). As a result, centralized networks are not well suited for interdependent tasks that require input from many team members (Katz et al. 2004). In this paper, we focus on interdependent tasks and, therefore, will limit our theorizing about the impacts of structural capital to interdependent tasks.

In this study, structural capital represents both the number of exchanges (intensity) and the number of communicators (decentralization) within a team. Theory would suggest that structural capital and knowledge integration should be positively associated. Teams high in structural capital will have a history of more open and participative team discussions. These more open and participative team discussions will be characterized by certain positive and habitforming behaviors that will contribute to knowledge integration. One, teams will expect and wait for each team member to express his or her opinion and allow them time to offer an explanation. Two, these teams will also be more likely to have developed a habit of paying more attention to and utilizing other members' information. Third, individuals themselves are more likely to contribute information in teams that are high in structural capital (Vroom and Yetton 1973, De Dreu and West 2001).

In summary, higher structural capital increases the likelihood that more team members will contribute, share, and use information from all members. Lower levels of structural capital can indicate that team members have a history of not sharing and using information from all team members. Information sharing and using are fundamental to knowledge integration within teams (Tiwana and McLean 2005). As a result, we believe structural capital will influence knowledge integration within teams (Oh et al. 2004).

Hypothesis 3A (H3A). Structural capital is positively related to knowledge integration.

\section{Relational Capital and Knowledge Integration}

Although structural capital has a profound impact on the access to resources, those resources are inherently embedded in interpersonal relationships (Burt 2000). The relational dimension of social capital relates to the nature and quality of the relationships among team members and how those relationships affect behavior (Nahapiet and Ghoshal 1998). Relational capital is a joint resource available to team members and reflects the goodwill, collective bonds, and expectations of prosocial behavior that characterize relations (Adler and Kwon 2002, Putnam 2000, Coleman 1990). Relational social capital generates group solidarity and generalized reciprocity that helps overcome freeriding (Takahashi 2000, Yamagishi and Cook 1993). Extensive relational social capital has been shown empirically to enhance knowledge exchange among scientists (Bouty 2000), improve interunit interactions in multinationals (Kostova and Roth 2003), and increase new product development team performance (Hansen et al. 1999). Therefore, we believe relational capital has a significant impact on knowledge integration in teams.

Prior literature has viewed relational capital as consisting of four subdimensions: identification, trust, obligations, and norms (Nahapiet and Ghoshal 1998, 
Wasko and Faraj 2005). These subdimensions reflect the quality of ties among network members and represent the motivation that an individual has to exchange resources within that network. In short, team members are more likely to exchange resources within a team when they identify with the team, trust the team, perceive an obligation to the team, and are willing to abide by the team's norms. The relationship between each subdimension and knowledge integration is discussed below.

Trust. Trust impacts knowledge integration in two ways. First, trust allows individuals to justify their decision to contribute and enables the exchange of more useful information (Brewer 1981, Kramer and Goldman 1995, Kramer et al. 1996). Second, trust enables individuals to freely exchange information that is critical to the success of collaboration (Davenport and Prusak 1998). In particular, higher levels of trust improve knowledge integration by increasing the amount (Dirks and Ferrin 2002) and types of information exchanged (Andrews and Delahaye 2000). Trust also facilitates the use of information (Nahapiet and Ghoshal 1998), as it increases the credibility of information and thus increases the likelihood that team members will consider using that information in their deliberations (Dennis 1996).

Team Norms. Team norms are shared standards or rules, both implicit and explicit, which govern the behavior and perceptions of members (Cohen et al. 1996, Feldman 1984). Team norms influence the knowledge integration process by enhancing a team's ability to provide and elicit information from team members by providing structure for team discussions (Deeter-Schemlz and Ramsey 2003). These norms support task debates and suppress personal attacks of team members (Wittenbaum et al. 2004), which promotes a cooperative motivational environment encouraging risk taking and tolerance of mistakes (Caldwell and O'Reilly 2003). The presence of strong team norms positively increases knowledge integration.

Obligations. Obligations are feelings of mutual responsibility that exist among team members (Nahapiet and Ghoshal 1998, Coleman 1990). Nahapiet and Ghoshal (1998) posited that obligations would influence both access and motivation for exchanging and integrating knowledge among individuals. Teams high in mutual obligations will have members who are more committed to sharing their information, as well as to using another team's information to reach an optimal solution, and they will be less likely to engage in social loafing and to withhold information from the team.

Team Identification. Team identification is defined as "the extent to which members are psychologically identified with a group" (Scott 1997, p. 120). Teams high in identification will have members who will be motivated to help maintain a positive team identity (Hogg et al. 2004, Abrams and Hogg 1990). Members of decision-making teams will see the team's success as their own success and see a connection between their actions and the team's achievement (Alles and Datar 2002). Thus, members will be more motivated to ensure team success and engage in productive behavior such as the sharing of information during team discussions. Strong team identification increases the amount and effectiveness of communication and information exchange among team members (Towry 2003).

In summary, the more team members identify with the team, trust the team, perceive an obligation to the team, and are willing to abide by the team norms, the more they will share information with the team and use information provided from other team members. Therefore, we hypothesize that relational capital (team trust, norms, obligations, and identification) will facilitate knowledge integration.

Hypothesis 3B (H3B). Relational capital is positively related to knowledge integration.

\section{Cognitive Capital and Knowledge Integration}

Cognitive capital represents the extent to which members share a common understanding (shared meaning and expectations) about their teamwork and/or task (Mathieu et al. 2000). Individual mental models are organized knowledge structures that are symbolic representation of reality, socially constructed by individuals to interpret and interact with the world around them (Carley 1997). Shared mental models exist when members have similar knowledge structures (Cannon-Bowers et al. 1993). Shared mental models for the team's task enable members 
"to form accurate, explanations, and expectations" about the task, which in turn, enables members "to coordinate their actions and adapt their behavior to [the] demands of the task" (Cannon-Bowers et al. 1993, p. 228). Shared mental models can be developed when members have similar experiences that can be imported into situations, whether those experiences were developed jointly as a team or separately through individual action (Ellis 2006, Madhavan and Grover 1998).

Shared mental models are important for effective exchange and integration of information (Nahapiet and Ghoshal 1998). Shared mental models enable high-performing teams to coordinate their efforts without a need to communicate overtly (Lim and Klein 2006, Edwards et al. 2006, Mathieu et al. 2005, Mathieu et al. 2000, Cannon-Bowers et al. 1993). When team members have similar knowledge structures, they are able to predict what is needed by their teammates to accomplish a task with less need to communicate overtly (Cannon-Bowers et al. 1993). This cognitive similarity is considered a "bonding mechanism" that aid in the integration of knowledge (Inkpen and Tsang 2005). It provides team members with a cognitive map on where and how information should be organized to accomplish a task. This enables teams to rapidly process information into meaningful models, increasing the efficiency and effectiveness of information exchange among team members (Marks et al. 2002). This reduces the cognitive load on the team and increases the likelihood that all information, both shared and unshared, will have a better chance of being evaluated (Heninger et al. 2006). In short, a shared understanding facilitates the exchange of meaningful communication needed for exchange and combination for knowledge creation (Nahapiet and Ghoshal 1998, Li 2005).

Нypothesis 3C (H3C). Cognitive capital is positively related to knowledge integration.

\section{Social Capital and the Communication Environment}

We argue that social capital is important to knowledge integration in general, but it becomes much more important when teams communicate through lean digital networks. Communication through lean digital networks such as STM poses greater coordination challenges (Jarvenpaa et al. 1998, Piccoli and Ives
2003), leads to a reduction in meaning due the loss of verbal and nonverbal cues (Daft and Lengel 1986), and increases cognitive loads during the decision making process (Graetz et al. 1998, Straus 1996). In short, communication through lean digital networks is more problematic than communication that occurs face-to-face.

These challenges can be overcome, to some extent, by social capital. That is, presence of social capital helps counteract the detrimental effects of computer mediation on knowledge integration. Later in this paper, we argue that the impact of structural, relational, and cognitive capital on knowledge integration is stronger when communication occurs through lean digital networks: Teams with low social capital will have greater difficulty coping with the problems of lean networks, whereas teams with high social capital will be more likely to overcome them.

Structural capital helps to counteract the communication losses associated with lean digital networks. Many prior studies have assumed that the use of lean digital networks will inherently change the communication structure of teams (Ahuja and Carley 1999, Zack and McKenney 1995). In general, it is relatively easier to ignore others' communication, as well as to neglect making one's own contribution in digital environments (Dennis 1996, Kiesler et al. 1984). However, teams with established structural social capital will tend to import their prior communication structures into the new communication environments (Straus 1996, Zack and McKenney 1995). Teams that are high in structural capital will have a history of engaging in more open and participative discussions. As a result, members in these teams will be more responsive and attentive to their other team member's information, even in environments in which they could easily ignore other members. Decentralized networks facilitate a more distributed information exchange, thus reducing the social loafing in the group. The reverse is also true. The role of structural capital in knowledge integration becomes critical when one is communicating through lean digital networks, where members can easily move on to another topic without noticing whether all members have contributed to the decision making process. As a result, structural capital will be more important to knowledge integration when one is communicating through lean digital networks. 
Hypothesis 4A (H4A). The positive relationship between structural capital and knowledge integration is stronger when teams communicate through lean digital networks.

Relational capital helps to diminish the negative impacts of lean communication. When relational social capital based on trust members are more likely to be accepting of information that is shared by others. They will also be forgiving and understanding of why others behave the way they do (e.g., not being able to share immediately). If trust-based relational capital is low, misunderstandings are more likely to occur and defenses will be high. As a result, knowledge integration is less likely to occur. Trust will not only encourage more information sharing among team members who communicate through digital networks but also will ensure the use of that information. Thus, presence of trust helps counteract the detrimental effects of computer mediation on knowledge integration.

Team norms that encourage sharing and cooperation will enhance the ability of their members to provide and elicit information from each other, helping team members overcome communication barriers associated with the use of lean digital networks. Both strong team identity and obligations will reduce the likelihood of members ignoring other's messages when it becomes easier to do so. Teams that are high in both will be motivated and committed to overcoming the communication barriers of lean media and will share and use information to reach the optimal solution. These members will not only feel a sense of mutual responsibility for the team success (Blau 1964, Shore and Barkdale 1998) but will also see the team success as their own personal success (Hogg et al. 2004, Abrams and Hogg 1990), justifying the additional effort involved in the use of lean digital networks. In short, teams high in relational capital will be able to compensate for the problems associated with the use of lean digital networks.

Нypothesis 4B (H4B). The positive relationship between relational capital and knowledge integration is stronger when teams communicate through lean digital networks.

Cognitive capital, the similarity in members' mental models, is more important to knowledge integration when communication is problematic and restrictive (Mathieu et al. 2000). This shared context helps reduce the negative impacts of communication through lean digital networks. First, it reduces the cognitive load, as well as the need to exchange context-related information needed to reach a shared understanding. Similarities in mental models provide members with a framework to conduct the task, allowing members to predict what information is important to others. This enhances coordination among members and increases the efficiency of communication while reducing the cognitive load-all of which compensates for the communication losses inherent in lean digital networks.

The shared context also reduces the length and complexity of messages (Maznevski and Chudoba 2000, Cohen et al. 1996). This phenomenon has two implications. Because communication through lean digital networks can be more cumbersome than faceto-face communication, team members may not communicate all the needed information about a task (Graetz et al. 1998). However, the shared context requires less communication to share and use the same amount of information, which reduces the chance of team members not sharing and not using all relevant information. Because so much context is already shared, members can focus on integrating new information (the unique information they do not possess) thereby reducing the cognitive load. In addition, the shared context helps provide meaning to information that is exchanged, somewhat compensating for the loss of verbal and nonverbal cues when communicating through lean digital networks. Teams high in cognitive capital will be better able to adapt to the constraints imposed by the use of lean digital networks. Thus, we would expect the relationship between cognitive capital and knowledge integration to strengthen when teams communicate through lean digital networks.

Hypothesis 4C (H4C). The positive relationship between cognitive capital and knowledge integration is stronger when teams communicate through lean digital networks.

\section{Method}

\section{Subjects}

The subjects were junior-level business school students from a large state university. At the beginning 
of the study, 184 subjects were recruited to participate, of which 172 subjects chose to complete all parts of the study. Of these 172 subjects included in our analyses; $34 \%$ were female. Ages ranged from 20 to 29 years with an average of 21.4. There were 46 teams, ranging from 3 to 5 members, with a mean of 4.1 and a mode of 4 members. Prior to the experiment, the teams worked together for 6 to 9 weeks to complete several team assignments. This was done to allow teams to build social capital. After the experiment, the teams worked together to complete additional assignments for another 4 to 7 weeks. Thus, the experiment is a snapshot taken in the middle of the lives of these intact, operating teams.

\section{Tasks}

The teams completed two tasks, one in each communication environment, which asked them to select which students from a set of 10 applicants to admit to the university. Both tasks were structured and administered the same way. Teams were given 1 hour for the first task and 45 minutes for the second task. The tasks were hidden profile tasks, as defined by Stasser and Stewart (1992), and would be classified as an intellective task by McGrath (1984). A hidden profile task was selected because of its highly interdependent nature. Each team member was given incomplete information on 10 high school students applying to a university. To encourage discussion about every applicant, the teams were allowed to admit only 6 of the 10 students. This task was chosen because every member of the team had prior experience with the university admission process, as they had successfully navigated it themselves (see Dennis 1996). Each team member received common information known to everyone, shared information known to at least two members, and unique information known only to him or her. To complete the task correctly, team members needed to share the unique information and use it in their decision making. The information elements were randomly assigned to subjects on a team. Each team member was given a different information element distribution per applicant. Teams that had three or five members received the same information set as four-member teams, but the distribution of information across team members was slightly different (although the basic pattern of common, shared, and unique information was essentially the same).

\section{Independent Variables}

The communication environment was manipulated between face-to-face communications and STM. In the face-to-face treatment, team members sat around a table and engaged in open discussion. They were given a pad of paper to record any information that they felt was important to the team decision. In the STM treatment, team members sat in separate rooms and communicated only through the synchronous text communication environment. The communication software used for this experiment was the Sakai course management software. Sakai provides an online communication environment that allows communication through email, chat rooms, and discussion forums, but for this experiment, participants were only allowed to use one chat room. Overall, the software was similar to most chat room software; team members entered text in one window and could read the comments of others in another window. They could scroll up and down to read any previous message and could also see the names of the person who contributed each comment. The communication environment was put into the model as a dummy variable. This was done by using 0 to represent faceto-face communication and 1 to represent communication through lean digital networks.

One of the strengths of this study is that we measured each of the three dimensions of social capital prior to the experiment. Therefore, the three dimensions of social capital were not manipulated but, instead, were measured. Relational capital was measured at the individual level and aggregated to the team level (see the Analysis and Results for an assessment of this aggregation). Relational capital items (see Table 1) consisted of all four subcomponents described by Nahapiet and Ghoshal (1998): trust (Simons and Peterson 2000), identification (Brown et al. 1986), norms (Leonard-Barton 1995), and obligations (a new item). All items used a scale of 1 to 7 .

There are many ways to measure structural capital. We used the approach recommended by Rulke and Galaskiewicz (2000). The structural capital measurement was composed of both network decentralization and tie intensity. Decentralization is based on the degree of centrality (Freeman 1979), and intensity reflects strength of ties. Network decentralization and tie intensity was determined by asking each team 
Table 1 Question Items

\begin{tabular}{|c|c|c|}
\hline Item & Question & Source \\
\hline Relational capital (norms) (1) & There is a norm of teamwork in this team. & Goodman and Darr (1998) \\
\hline Relational capital (identification) (2) & I find it easy to identify myself with this team. & Brown et al. (1986) \\
\hline Relational capital (trust) (3) & $\begin{array}{l}\text { Given my teammates previous performance, } \\
\text { I see no reason to doubt their competence } \\
\text { and preparation for another team task. }\end{array}$ & McAllister (1995) \\
\hline Relational capital (obligation) (4) & $\begin{array}{l}\text { Most, if not all, the members of my team felt } \\
\text { mutually responsible for the team's performance. }\end{array}$ & New item \\
\hline Network structure (1) & How much did you depend on ___ ? & Rulke and Galaskiewicz (2000) \\
\hline Network structure (2) & How much did ___ depend on you? & Rulke and Galaskiewicz (2000) \\
\hline Network structure (3) & How much did you work with ___ ? & Rulke and Galaskiewicz (2000) \\
\hline Network structure (4) & How much did you communicate with & Rulke and Galaskiewicz (2000) \\
\hline
\end{tabular}

member to rate how much they worked with, communicated with, and depended on other team members (see network questions in Table 1). The scores were aggregated across the four network items, producing an average tie value between members, which were then averaged across all pairs in a team. A detailed description of this computation is available as an online supplement. ${ }^{1}$

We operationalized cognitive capital as the shared common understanding of taskwork among team members, the degree to which members shared a common understanding of what was important to the task (Mathieu et al. 2000, 2005). Cognitive capital was measured by using a repertory grid analysis technique called sociogrid to assess the extent to which the team had a shared mental model (Shaw and McKnight 1981). Sociogrids measure the similarity between these individual mental models (Alexander and Van Loggerenberg 2005) — "the extent that one person employs a construction of experience that subsumes that of another in a given domain" (Shaw, no date). The first step was to obtain individual repertory grids by having individuals rate how important each decision criterion (GPA, SAT, student's home town, etc.) was to their individual decision prior to any team interactions, using a scale from 1 to 7 .

We used the Rep IV 1.12 software to analyze the sociogrids for each individual in each team. The software used hierarchical cluster analysis to compare

\footnotetext{
${ }^{1}$ All proofs are contained in an online appendix to this paper that is available on the Information Systems Research website (http://isr. pubs.informs.org/ecompanion.html).
}

each individual repertory grid to all others in the same team to calculate the average distance between team members. This analysis yielded a commonality index that represents the extent to which members agreed on what was important to the decision (Shaw and McKnight 1981). The scores range from 0 to 1 , with 0 indicating no similarity between members and 1 indicating that members rated the criteria the same. Although members likely would not have discussed the importance of admission criteria prior to this experiment, their prior individual and team experiences could help shape their views on the relative importance of SAT versus GPA, of admitting in-state versus out-of-state students, of extracurricular activities, etc. Additional information is provided in the online supplement.

\section{Dependent Variables}

Knowledge integration was measured as a formative construct that consisted of two subconstructs measuring the sharing of information and the use of task information. The first, information sharing, was calculated following the procedures of Dennis (1996). Two independent raters blind to the hypotheses coded whether each unique piece of information (i.e., known only to one person) was present or absent in the discussions of each team (verbal transcripts for the face-to-face task and electronic transcripts for the STM task). We counted the number of unique pieces of information in each discussion to produce the team's information sharing score for that discussion, the total number of pieces of unique informa- 
tion contributed. Interrater reliability was adequate: Cohen's (1960) kappa of 0.95.

The second knowledge integration subconstruct, the use of unique information, was calculated following a similar process. Two independent raters blind to the hypothesis coded whether each piece of unique information was referred to by a subject other than the person who initially stated it. This coding scheme was binary, referred to or not referred to, for each unique of piece information. We then counted the number of unique pieces of information referred to each discussion to produce the team's information use score, the total number of unique of pieces information used by someone other than the initial contributor. Interrater reliability was adequate: Cohen's (1960) kappa of 0.78. Examples of the coding of the sharing and use of unique information are in the online supplement.

Decision quality was measured by the number of correct decisions the team made. Each task required the teams to select which of 10 applicants should be admitted or rejected. Two admission officers from the same university attended by the subjects independently identified which applicants should be admitted and rejected. The two admission officers had an $87 \%$ agreement prior to resolving their differences. Decision quality was measured by counting the number of each team's admit/reject decisions that matched the experts' decisions, resulting in a score from 0 to 10 for each task (10 would indicate that the team's admit/reject decisions perfectly matched the experts' decisions on all 10 applicants in the set).

\section{Control Variables}

We were concerned that team size and task order would impact both knowledge integration and decision quality. Therefore, team size and task order were used as control variables in both models. Team size was measured by including the number of team members as a variable in the model. Task order was measured by including a 1 or 2, 1 indicating the first task and 2 indicating the second task. The type of communication environment was included as a control variable in the decision quality analysis. We wanted to control for the effects of communication media while testing for the main effect of knowledge integration.

\section{Procedures}

Teams were formed within the second week of the normal 15 week semester and worked together to complete several assignments. Between the sixth and eighth weeks of class, individual team members completed a questionnaire measuring relational and structural capital. Each team performed the experiment in the 9th or 10th week of class (6-10 days after completing the questionnaire). The experimental facility consisted of one open lab and five breakout rooms, each containing one computer. Team members were greeted and briefed in the open lab and then placed separately into breakout rooms. Once in the breakout rooms, team members could not see each other, nor could they communicate verbally.

Each team member was given the first task and made an individual decision about each applicant in the task (working alone in a breakout room without interacting with other team members). They then individually filled out a repertory grid that was used as input to the cognitive capital calculations.

At this point, team discussion of the first task began. Half of the teams were randomly assigned to the face-to-face treatment first and half were assigned to the STM treatment. Teams assigned to the STM treatment were trained on the software and began using it from their individual breakout rooms to discuss the task. Teams assigned to the face-to-face environment moved into the open lab and sat around a table; once the face-to-face teams made their decision, members returned to their individual breakout rooms.

Each team member was then given the second task and made an individual decision about each applicant (working alone in a breakout room without interacting with other team members). At this point, team discussion of the second task began. Teams completed the second task following the same procedures described above but did so using the other communication environment.

Subjects were then debriefed and released. The entire experiment lasted a total of 2 hours.

\section{Analysis and Results}

\section{Construct Validities and Reliabilities}

The team level latent variable, relational capital was captured at the individual level so a team-level measure needs to be aggregated from individual team 
member responses. Two interclass correlation coefficients (ICC) were calculated to justify the aggregation of individual level data to team level data. The first, ICC(1), was used to determine the within-team agreement or the extent to which one team member's responses represents that of the entire team (Bliese 2000). The second, ICC(2), was used to determine the reliability of the group means within a sample (Klein and Kozlowski 2000). ICC(1) values that exceed 0.30 are considered acceptable for team aggregation (Bliese 2000). ICC(2) values that exceed 0.70 are considered acceptable for team aggregation (Klein and Kozlowski 2000). The ICC(1) for relational capital was 0.65 , while the ICC(2) was 0.88 , so we conclude that aggregation is appropriate.

Knowledge integration was measured as a formative construct that consists of two subconstructs. The direction of causality is from the indicators to the construct, and the items are not interchangeable, both of which provided justification for modeling knowledge integration as formative rather than reflective construct (Jarvis et al. 2003). The correlation matrix of the model is shown in Table 2 . The average variance shared is indicated by average variance extracted (AVE), shown along the diagonals of a correlation matrix. The AVE of each construct is larger than its corresponding row and column correlations, providing support for convergent and discriminant validity (Fornell and Larcker 1981). The reliability of the measurements was tested using Fornell's internal composite reliability (ICR) and is also listed in Table 2 (Fornell and Larcker 1981). All latent constructs' ICR were above 0.70 , indicating sufficient reliability (Fornell and Larcker 1981, Nunnally 1978). Nonlatent variables did not have reliability scores, so they were listed as "n/a."

\section{Manipulation Checks}

To ensure that the participants did have to exchange information to reach the correct solution, the effectiveness of the manipulation was assessed. If team decision quality scores were higher than the average of the individual prediscussion decision quality scores in each team, this would provide evidence that exchanging information led to higher scores. A repeated measures means test was performed between the average individual preteam discussion scores and the team score. Team scores were significantly higher than the average individual preteam discussion score $(F=4.8$, $p<0.05)$. We conclude that the manipulation was successful.

\section{Structural Model Assessment}

The research model was tested with PLS graph 3.0. In this study, repeated measures were treated as separate sample cases, which would be problematic with ordinary least squares regression (OLS), because this violates the OLS assumption that the sample cases are independent (Neter et al. 1996). However, with PLS "no assumptions are made regarding the joint distribution of the indicators or the independence of sample cases." (Chin 1998, p. 332). As a result, this approach is appropriate when using PLS.

Knowledge integration is modeled as formative construct, so the ability of PLS to model both formative as well as reflective constructs makes it suitable for our purposes. The statistical significance of the parameter estimates tested with PLS was determined by a bootstrapping procedure. All the independent variables were standardized, with the exception of the categorical variables (communication environment and task order). The moderation variables were calculated by multiplying each standardized

Table 2 Correlations of Latent Variables

\begin{tabular}{lccccccccc}
\hline & Mean & S.D. & ICR & Team size & $\begin{array}{c}\text { Team decision } \\
\text { quality }\end{array}$ & $\begin{array}{c}\text { Knowledge } \\
\text { integration }\end{array}$ & $\begin{array}{c}\text { Structural } \\
\text { capital }\end{array}$ & $\begin{array}{c}\text { Cognitive } \\
\text { capital }\end{array}$ & $\begin{array}{c}\text { Relational } \\
\text { capital }\end{array}$ \\
\hline Team size & 4 & 0.56 & $\mathrm{n} / \mathrm{a}$ & 1 & & & & & \\
Team decision quality & 5.27 & 1.12 & $\mathrm{n} / \mathrm{a}$ & -0.040 & 1 & & & \\
Knowledge integration & 5.99 & 0.53 & $\mathrm{n} / \mathrm{a}$ & -0.022 & $0.593^{* * *}$ & 1 & & & \\
Structural capital & 0.57 & 0.17 & $\mathrm{n} / \mathrm{a}$ & $0.351^{*}$ & 0.116 & 0.117 & 1 & & \\
Cognitive capital & 53.5 & 7.55 & $\mathrm{n} / \mathrm{a}$ & -0.130 & 0.239 & $0.448^{* *}$ & -0.077 & 1 & \\
Relational capital & 4.69 & 0.55 & 0.92 & 0.176 & 0.089 & $0.343^{*}$ & 0.188 & 0.060 & 0.731 \\
\hline
\end{tabular}

Notes. Average variance extracted is reported on the diagonals. ${ }^{*} p<0.05,{ }^{* *} p<0.01,{ }^{* * *} p<0.001$. 
Table 3 Dependent Variable: Decision Quality

\begin{tabular}{llrcccccc}
\hline Hypothesis & \multicolumn{1}{c}{ Factor } & $\beta$ & $t$-value & $\begin{array}{c}\text { Significance } \\
\text { level }\end{array}$ & $R^{2}$ & Adjusted $R^{2}$ & $F_{(4,41)}$ & $\begin{array}{c}\text { Model significance } \\
\text { level }\end{array}$ \\
\hline Control variable & Team size & -0.027 & 0.307 & Nonsig. & $36.4 \%$ & $30.20 \%$ & 5.86 & 0.001 \\
Control variable & Task order & 0.089 & 1.03 & Nonsig. & & & & \\
Control variable & Communication medium & -0.067 & 0.70 & Nonsig. & & & & \\
H1 & Knowledge integration & $\mathbf{0 . 5 9 2}$ & $\mathbf{3 . 6 6}$ & $\mathbf{0 . 0 0 1}$ & & & & \\
\hline
\end{tabular}

independent variable by the moderating variable (Chin et al. 2003).

Hypothesis 1, that knowledge integration is positively related to team decision quality, was supported. Knowledge integration $(\beta=0.592, p<0.001)$ was a significant positive predictor of decision quality, explaining $36.4 \%$ of the variance $\left(F_{4,41}=5.86, p<\right.$ $0.001)$; team size $(\beta=-0.027 ; p>0.10)$, task order $(\beta=0.089 ; p>0.10)$, and communication environment $(\beta=-0.067 ; p>0.10)$ were nonsignificant (see Table 3).

Hypotheses 2 (communication environment), H3A (structural capital), H3B (relational capital), and H3C (cognitive capital) proposed main effects of these factors on knowledge integration. Hypotheses $\mathrm{H} 2(\beta=$ $0.013 ; p>0.10)$ and H3A $(\beta=0.075 ; p>0.10)$ were not supported, whereas both $\mathrm{H} 3 \mathrm{~B}(\beta=0.359 ; p<0.01)$ and H3C $(\beta=0.483 ; p<0.01)$ were supported. Communication environment and structural capital had no main effects on knowledge integration, but relational capital and cognitive capital both positively impacted knowledge integration.
Hypothesis 4 stated that the positive relationship between each dimension of social capital and knowledge integration should be stronger when teams use lean digital networks. The interaction between structural capital and communication environment was significant $(\beta=0.166 ; p>0.05)$, as was the interaction between cognitive capital and communication environment $(\beta=0.121 ; p>0.05)$; the interaction between relational capital and communication environment was not significant $(\beta=0.055 ; p<0.10)$ (see Table 4). We conclude that H4A (structural capital) and $\mathrm{H} 4 \mathrm{C}$ (cognitive capital) are supported, but $\mathrm{H} 4 \mathrm{~B}$ (relational capital) is not; in other words, structural and cognitive capital were more important to knowledge integration when teams communicated through lean digital networks, whereas relational capital was equally important to knowledge integration, whether teams communicated face-to-face or through lean digital networks. The variance explained in the model was $35.4 \%\left(F_{9,36}=2.19, p<0.05\right)$.

The significant moderation effects are plotted in Figures 2 and 3. Figure 2 depicts the moderation effect of structural capital on the relationship between the

Table 4 Dependent Variable: Knowledge Integration

\begin{tabular}{|c|c|c|c|c|c|c|c|c|}
\hline Hypothesis & Factor & $\beta$ & $t$-value & $\begin{array}{l}\text { Significance } \\
\text { level }\end{array}$ & $R^{2}$ & Adjusted $R^{2}$ & $F_{(9,36)}$ & $\begin{array}{l}\text { Model significance } \\
\text { level }\end{array}$ \\
\hline Control variable & Team size & -0.019 & 0.17 & Nonsig. & $35.4 \%$ & $19.25 \%$ & 2.192 & 0.05 \\
\hline Control variable & Task order & -0.013 & 0.13 & Nonsig. & & & & \\
\hline $\mathrm{H} 2$ & Communication medium & 0.013 & 0.12 & Nonsig. & & & & \\
\hline $\mathrm{H} 3 \mathrm{~A}$ & Structural capital & 0.075 & 0.57 & Nonsig. & & & & \\
\hline H3B & Relational capital & 0.359 & 3.42 & 0.01 & & & & \\
\hline $\mathrm{H} 3 \mathrm{C}$ & Cognitive capital & 0.483 & 3.39 & 0.01 & & & & \\
\hline $\mathrm{H} 4 \mathrm{~A}$ & $\begin{array}{l}\text { Structural capital } \\
\quad \times \text { communication medium }\end{array}$ & 0.166 & 2.12 & 0.05 & & & & \\
\hline H4B & $\begin{array}{l}\text { Relational capital } \\
\quad \times \text { communication medium }\end{array}$ & 0.055 & 0.42 & Nonsig. & & & & \\
\hline $\mathrm{H} 4 \mathrm{C}$ & $\begin{array}{l}\text { Cognitive capital } \\
\times \text { communication medium }\end{array}$ & 0.121 & 2.14 & 0.05 & & & & \\
\hline
\end{tabular}


Figure 2 Structural Capital as a Moderator of the Relationship Between Communication Environment and Knowledge Integration

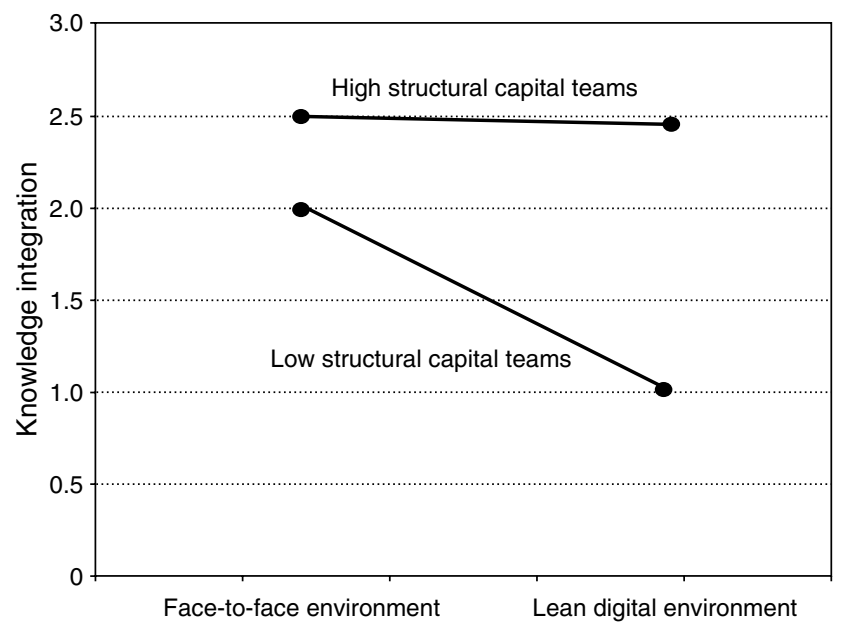

communication environment and a team's ability to integrate knowledge. When structural capital is low, the ability of teams to integrate knowledge through digitally enabled networks is low when compared to face-to-face abilities. However, when structural capital is high, those differences are eliminated; use of lean digital networks is as effective as face-to-face interaction. A similar relationship is observed in Figure 3 with cognitive capital. High levels of cognitive capital enable teams that communicate through digi-

Figure 3 Cognitive Capital as a Moderator of the Relationship Between Communication Environment and Knowledge Integration

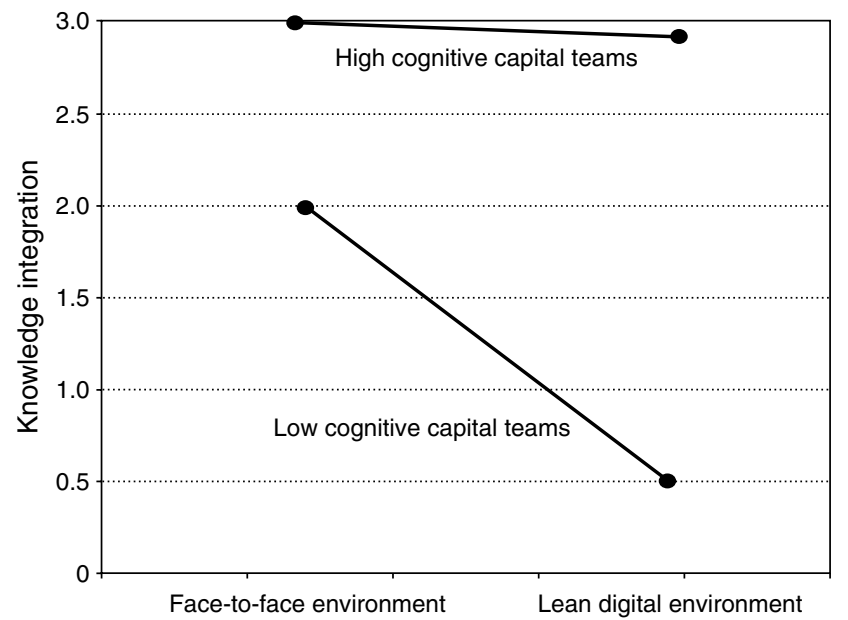

tal networks to integrate knowledge at levels similar to those of face-to-face environments. However, low cognitive capital teams face challenges with lean digital networks.

\section{Discussion and Implications of Results}

The goal of this study was to examine the effects of the three dimensions of social capital-structural, relational, and cognitive-on knowledge integration and team performance in two different communication environments. By studying all three dimensions simultaneously, we were able to see what impact each dimension had in the presence of the other two. This is important, because if we had tested only one dimension of social capital, we would not have been able to determine if that dimension would have remained significant in the presence of the other two dimensions.

The results of this study indicate that all three dimensions of social capital affect knowledge integration in teams and that knowledge integration in turn has a direct impact on team performance for interdependent tasks. Relational capital is positively related to knowledge integration and is equally important whether team communication takes place face-to-face or through lean digital networks; that is, teams with greater relational capital are more likely to exchange and use the unique information and knowledge available to individual team members, regardless of communication environment. Structural and cognitive capital are even more critical to knowledge integration when teams communicate through lean digital networks. For teams with low structural or cognitive capital, use of lean digital networks pose a serious threat to performance. Teams with high structural and cognitive capital will experience little performance impacts when using lean digital networks.

Previous research suggests that the use of lean digital networks can encourage more even participation (Kwok et al. 2002, Hollingshead 1996). However, this study found that although technology can facilitate equal participation, the team's social network structure formed by digital communication, imported from their prior history of interactions, enabled and/ or constrained the knowledge integration process, so that teams with a more centralized structure exchanged and used less information. In other words, 
despite the fact that every team member had the equal ability to send and read messages in the digital environment, the team's social network structure influenced the information that was actually sent and to what information team members actually paid attention. This is consistent with previous findings that centralization reduces participation and creation of new ideas in interdependent tasks. This may explain why many studies have shown that the use of lean digital networks increases participation but has little impact on team performance.

Cognitive capital also was more critical when team members communicated through lean digital networks. When similarities among mental models were high, members were more likely to integrate knowledge-to share information that others thought was important and to act on it. When similarities were low, members may have provided too much information that other members thought was unimportant or too little information that other members might have found important. The effect was stronger when team members communicated through lean digital networks, perhaps because members may have found it much more difficult to break into team discussions and request more or specific information, unlike with face-to-face environments, where it is easier to get other team members' attention and harder to ignore their requests. This means that establishing a shared understanding is even more important when teams use lean digital networks. These results are important because no prior research has directly examined the interplay between a team's cognitive capital and the digital networks they use to communicate.

A lack of team history has been put forth as an explanation as to why teams that communicate through CMC cannot perform as well as face-to-face (cf. van der Kleij et al. 2005, Alge et al. 2003, Hollingshead et al. 1993, McGrath and Hollingshead 1993). In particular, Alge et al. (2003) found that once teams develop a history, they are able to perform as well as face-to-face teams; yet, at least one study, Mennecke and Valacich (1998), found that team history had no impact on team performance. This argument also ignores that fact that teams can develop a bad history (Piccoli and Ives 2003), which could hinder performance.
We offer another explanation; we believe that team history offers an opportunity for teams to develop social capital and that it is social capital, not history per se, that compensates for the greater process losses in CMC. In essence, the shared context that increases the bandwidth of lean media in studies by Lee (1994) and Carlson and Zmud (1999) may, in fact, be because of the development of social capital. It is social capital that helps to overcome the problems inherent in lean media, not history.

Finally, no one stream of research has exemplified the importance of knowledge integration within teams more than the hidden profile paradigm. The early hidden profile studies assumed that if team members exchanged unique information, they would integrate it and reach the correct solution, but empirical results have not supported this; in fact, even in cases when team members share more unique information, they often do not reach the correct solution (Dennis 1996, Hollingshead 1996, McLeod et al. 1997). Understanding why team members fail to integrate each other's knowledge is thus an important riddle that remains unsolved (Heninger et al. 2006). Our results indicate that social capital may be one of the keys to this riddle; teams with higher social capital are more likely to integrate (i.e., exchange and use) the unique information their members hold. These results have important implications for theory (in our study, increased social capital led to better knowledge integration), empirical research (most prior research on hidden profile tasks has used ad hoc teams with no opportunity to develop social capital), and practice (knowledge integration problems found in prior research with ad hoc teams may be less common in organizations, at least in teams with higher social capital).

As with all research, this study has several limitations. We used established teams of student subjects who might behave differently than managers and professionals. The task was an admission task, so the subjects should be familiar with the task context, as the admission process has become more competitive, requiring applicants to invest more time in the application process (Alon and Tienda 2007). Although the lack of prior experience with this specific task may have affected behavior, we saw no significant differences because of task order, which would suggest 
that this was not a major concern. Experimental settings have been criticized as being artificial, leading to results that may not hold up in "natural settings." We do not refute this claim but argue that the setting for this study (ongoing teams, familiar technology, familiar task context) was reasonable for these subjects.

Another limitation is the operationalization of cognitive capital. In this study we used team mental models of the task to operationalize cognitive capital (Mathieu et al. 2000). As a result, cognitive capital was not the direct result of a team member's prior interaction over time, as the teams had not worked on admissions tasks prior to the experiment. As such, cognitive capital was the only dimension of social capital that we could expect team members to import from their personal experiences, not team experiences.

\section{Implications for Research}

Understanding the problems causing poor knowledge integration teams, regardless of their communication environment and finding ways to overcome them, has been a subject of a major stream of research over the last two decades. Our results show that social capital directly affects knowledge integration (accounting for about $20 \%$ of the variation, which Cohen (1988) would consider a medium-size effect) and that social capital has a stronger impact in lean digital environments. Thus, one key to the knowledge integration puzzle lies in social capital. We believe that this calls for more research into the impacts of social capital on knowledge integration. Much prior research on knowledge integration, particularly that using hidden profile tasks in experimental settings, has used ad hoc teams that had no opportunity to develop social capital. It may be that the findings of this research may not generalize well to teams with high social capital working in organizational settings.

Prior research has shown that elements of social capital are harder to develop when teams use lean digital media (Chidambaram 1996). Yet, our results show that social capital is more important when teams use lean digital media than when they interact face to face. This suggests an interesting conundrum: If social capital is more important, yet harder to create, how can we change digital media or the way in which teams use them to improve the development of social capital where it is most needed?
Much prior research has examined relational capital and its subdimensions, such as trust and norms. Far less research attention has been devoted to obligations and identification, at least for research in digital environments. Our results show that relational capital is important, but no more important when using lean digital environments than when communicating face to face. We conclude that it may be useful to increase research attention on the less studied other subdimensions (i.e., obligations and identification) and on the structural capital and cognitive capital that are more important in digital environments.

Additional research should examine how social capital develops through digital networks when there is no history. For example, what situational and environmental factors influence the network structure of teams? Most digitally enabled teams that are studied are treated as self-directed teams, which are also common in organizational settings. What causes self-directed teams to produce a highly intense-decentralized network structure versus a low intense-centralized network structure? Are teams that communicate primarily through digital networks more likely to have a highly intense-decentralized network structure? Digitally enabled teams are often composed of members from diverse cultural background: Will the use of digital networks help or retard the development of cognitive capital within these teams?

\section{Implications for Practice}

This study suggests that social capital is important for knowledge integration and performance and that structural capital and cognitive capital are more important when teams communicate through lean digital media. This has several implications. First, although relational capital and its subdimensions (e.g., trust) have been the focus of much attention, it is important not to overlook the other dimensions of social capital (i.e., structural capital and cognitive capital), which are especially important when using lean digital media.

Second, managers should manage the development of their team's social network structure. For highly complex and interindependent tasks, managers should strive to create a decentralized network structure. This could mean tasking team leaders with creating open, decentralized communication patterns. 
Managers should be careful when assigning team members, as some members have a long history together and others members have very little history, and this may lead to the development of cliques.

Third, managers should strive to create shared mental models among team members, especially for tasks performed using lean digital media. One suggestion is to have teams present their plan of action as early as possible and to encourage team members to begin to create a shared model of the task and work process early in the team development stage. Another recommendation would be for organizations to develop standard procedures on how organizational teams should function. This would in turn help facilitate a "teamwork" shared mental model among all their employees.

Despite the emergence of digitally enabled teams as a prominent organizational structure (Jarvenpaa et al. 1998), many questions remain about which factors actually influence the success of such teams. In this study, we found that relational capital directly impacted knowledge integration, regardless of the communication environment the team used. In contrast, structural capital and cognitive capital were more important to knowledge integration when teams communicated through lean digital networks. Knowledge integration, in turn, directly impacted team decision quality, suggesting that social capital influences team performance in part by increasing a team's ability to integrate knowledge.

\section{Acknowledgments}

The authors thank Wynn Chin for advice about the statistical analysis. We also thank the senior editor, associate editor, and reviewers for their helpful comments.

\section{References}

Abrams, D., M. A. Hogg. 1990. Social identification, selfcategorization, and social influence. Eur. Rev. Soc. Psych. 1 195-228.

Adler, P. S., S.-W. Kwon. 2002. Social capital: Prospects for a new concept. Acad. Management Rev. 27(1) 17-40.

Ahuja, M., K. Carley. 1999. Network structure in virtual organizations. Organ. Sci. 10(6) 741-747.

Ahuja, M., D. F. Galletta, K. Carley. 2003. Individual centrality and performance in virtual R\&D groups: An empirical study. Management Sci. 41(9) 21-38.

Alavi, M., A. Tiwana. 2002. Knowledge integration in virtual teams: The potential role of KMS. J. Amer. Soc. Inform. Sci. Tech. 53(12) 1029-1037.
Alexander, P. M., J. J. Van Loggerenberg. 2005. The repertory grid: Discovering a 50-year-old research technique. SAICSIT 2005, White River, Mpumalanga Province, South Africa, September, 20-22. South African Institute for Computer Scientists and Information Technologists, Republic of South Africa.

Alge, B. J., C. Wiethoff, H. J. Klein. 2003. When does the medium matter? Knowledge-building experiences and opportunities in decision-making teams. Organ. Behav. Human Decision Processes 91(1) 26-37.

Alles, M., S. Datar. 2002. Control implications of worker identification with firm sales success. Management Accounting Res. 13 173-190.

Alon, S., M. Tienda. 2007. Diversity, opportunity, and the shifting meritocracy in higher education. Amer. Sociol. Rev. 72(4) 487-511.

Andrews, K., B. L. Delahaye. 2000. Influences on knowledge processes in organizational learning: The psychosocial filter. J. Management Stud. 37(6) 797-810.

Baldwin, T. T., M. D. Bedell, J. L. Johnson. 1997. The social fabric of a team-based M.B.A. program: Network effects on student satisfaction and performance. Acad. Management J. 40(6) 1369-1397.

Baltes, B. B., M. W. Dickson, M. P. Sherman, C. C. Bauer, J. S. LaGanke. 2002. Computer mediated communication and group decision making: A meta-analysis. Organ. Behav. Human Decision Processes 87(1) 156-179.

Barki, H., A. Pinsonneault. 2005. The construct of organizational integration: A research framework and its application to enterprise systems research. Organ. Sci. 16(2) 165-179.

Bavelas, A. 1950. Communication patterns in task oriented groups. J. Acoustical Soc. America 22 272-283.

Blau, P. M. 1964. Exchange and Power in Social Life. John Wiley \& Sons, New York.

Bliese, P. D. 2000. Within-group agreement, non-independence, and reliability: Implications for data aggregation and analysis. K. J. Klein, S. W. J. Kozlowski, eds. Multilevel Theory, Research, and Methods in Organizations: Foundations, Extensions, and New Directions. Jossey-Bass, San Francisco, 349-381.

Borgatti, S. P., R. Cross. 2003. A relational view of information seeking and learning in social networks. Management Sci. 49(4) 432-445.

Bouty, I. 2000 Interpersonal and interaction influences on informal resource exchanges between $R \& D$ researchers across organizational boundaries. Acad. Management J. 43(1) 50-66.

Brass, D. J., J. Galaskiewicz, H. R. Greve, W. Tsai. 2004. Taking stock of networks and organizations: A multilevel perspective. Acad. Management J. 47(6) 795-817.

Brewer, M. B. 1981. Ethnocentrism and its role in interpersonal trust. M. B. Brewer, B. E. Collins, eds. Scientific Inquiry and the Social Sciences. Jossey-Bass, San Francisco, 214-231.

Brown, R. J., F. Condor, A. Mathews, G. Wade, J. A. Williams. 1986. Explaining intergroup differentiation in an industrial organization. J. Occupational Psych. 59(4) 273-287.

Burke, K., L. Chidambaram. 1999. How much media bandwidth is enough? A longitudinal examination of media characteristics and group performance. MIS Quart. 23(4) 557-580.

Burt, R. S. 2000. The network structure of social capital. R. I. Sutton, B. Staw, eds. Research in Organizational Behavior. JAI Press, Greenwich, CT, 345-423. 
Caldwell, D. F., C. A. O'Reilly. 2003. The determinants of teambased innovation in organizations: The role of social influence. Small Group Res. 34(4) 497-517.

Campion, M. A., G. J. Medsker, A. C. Higgs. 1993. Relations between work group characteristics and effectiveness: Implications for designing effective work groups. Personnel Psych. 46 $823-850$.

Cannon-Bowers, J. A., E. Salas, S. A. Converse. 1993. Shared mental models in expert decision making teams. N. J. Castellan, Jr. ed. Current Issues in Individual and Group Decision Making. Erlbaum, Hillsdale, NJ, 221-246.

Carley, K. M. 1997. Extracting team mental models through textual analysis. J. Organ. Behav. 18(S1) 533-558.

Carlson, J. R., R. W. Zmud. 1999. Channel expansion theory and the experiential nature of media richness perceptions. Acad. Management J. 42(2) 153-170.

Chidambaram, L. 1996. Relational development in computersupported groups. MIS Quart. 20(2) 143-165.

Chin, W. Y. W. 1998. The partial least squares approach for structural equation modeling. G. A. Marcoulides, ed. Modern Methods for Business Research. Lawrence Erlbaum Associates, Mahwah, NJ, 295-336.

Chin, W. Y. W., B. L. Marcolin, P. R. Newsted. 2003. A partial least squares latent variable modeling approach for measuring interaction effects: Results from a Monte Carlo simulation study and an electronic mail emotion/adoption study. Inform. Systems Res. 14 189-217.

Choo, C. W. 1998. The Knowing Organization: How Organizations Use Information to Construct Meaning, Create Knowledge, and Make Decisions. Oxford University Press, New York.

Cohen, J. 1960. A coefficient of agreement for nominal scales. Ed. Psych. Measurement 20(1) 37-46.

Cohen, J. 1988. Statistical Power Analysis for the Behavioral Sciences, 2nd ed. Erlbaum, Hillsdale, NJ.

Cohen, S. G., G. E. Ledford, Jr., G. M. Spreitzer. 1996. A predictive model of self-managing work team effectiveness. Human Relations 49(5) 643-676.

Coleman, J. S. 1990. Foundations of Social Theory. Harvard University Press, Cambridge, MA.

Daft, R. L., R. H. Lengel. 1984. Information richness: A new approach to managerial behavior and organizational design. L. L. Cummings, B. M. Staw, eds. Research in Organizational Behavior, Vol. 6. JAI Press, Homewood, IL, 191-233.

Daft, R. L., R. H. Lengel. 1986. Organizational information requirements, media richness and structural design. Management Sci. 32(5) 554-571.

Davenport, T. H., L. Prusak. 1998. Working Knowledge: How Organizations Manage What They Know. Harvard Business School Press, Cambridge, MA.

De Dreu, C. K. W., M. A. West. 2001. Minority dissent and team innovation: The importance of participation in decision making. J. Appl. Psych. 86(6) 1191-1201.

Deeter-Schmelz, D. R., R. P. Ramsey. 2003. An investigation of team information processing in service teams: Exploring the link between teams and customers. J. Acad. Marketing Sci. 31(4) 409-424.

Dennis, A. R. 1996. Information exchange and use in group decision making: You can lead a group to information but you can't make it think. MIS Quart. 20(4) 433-455.
Dennis, A. R., S. T. Kinney. 1998. Testing media richness theory in the new media: The effects of cues, feedback, and task equivocality. Inform. Systems Res. 9(3) 256-274.

Dennis, A. R., J. S. Valacich. 1994. Group, sub-group, and nominal group brainstorming: New rules for a new media? J. Management 20(4) 723-736.

Dennis, A. R., B. H. Wixom. 2002. Investigating the moderators of the group support systems use with meta-analysis. J. Management Inform. Systems 18(3) 235-257.

Dennis, A. R., K. M. Hilmer, N. J. Taylor. 1998. Information exchange and use in GSS and verbal group decision making: Effects of minority influence. J. Management Inform. Systems 14(3) 61-88.

Dennis, A. R., B. H. Wixon, R. J. Vandenberg. 2001. Understanding fit and appropriation effects in group support systems via meta-analysis. MIS Quart. 25(2) 167-193.

Dirks, K. T., D. L. Ferrin. 2002. Trust in leadership: Meta-analytic findings and implications for research and practice. J. Appl. Psych. 87(4) 611-628.

Edwards, B. D., E. A. Day, W. Arthur, Jr., S. T. Bell. 2006. Relationships among team ability composition, team mental models, and team performance. J. Appl. Psych. 91(3) 727-736.

Eisenhardt, K. M., M. A. Jeffrey. 2000. Dynamic capabilities: What are they? Strategic Management J. 21 1105-1121.

Ellis, A. P. J. 2006. System breakdown: The role of mental models and transactive memory in the relationship between acute stress and team performance. Acad. Management J. 49(3) 576-589.

Feldman, D. C. 1984. The development and enforcement of group norms. Acad. Management Rev. 9(1) 47-53.

Fornell, C., D. F. Larcker. 1981. Evaluating structural equations models with unobservable variables and measurement error. J. Marketing Res. 18(1) 39-50.

Freeman, L. C. 1979. Centrality in social networks: Conceptual clarification. Soc. Networks 1 215-239.

Galegher, J., R. Kraut. 1994. Computer-mediated communication for intellectual teamwork: An experiment in group writing. Inform. Systems Res. 5(2) 110-138.

Goodman, P. S., E. D. Darr. 1998. Computer-aided systems and communities: Mechanisms for organizational learning in distributed environments. MIS Quart. 22(4) 417-440.

Graetz, K. A., E. S. Boyle, C. E. Kimble, P. Thompson, J. L. Garloch. 1998. Information sharing in face-to-face, teleconferencing, and electronic chat groups. Small Group Res. 29(6) 714-743.

Grant, R. M. 1996a. Toward a knowledge-based theory of the firm. Strategic Management J. 17 109-122.

Grant, R. M. 1996b. Prospering in dynamically-competitive environments: Organizational capability as knowledge integration. Organ. Sci. 7(4) 375-387.

Gruenfeld, D. H., A. B. Hollingshead. 1993. Sociocognition in work groups: The integrative complexity of individual and group conceptualization. Small Group Res. 24(3) 362-382.

Hansen, M. T., N. Nohria, T. Tierney. 1999. What's your strategy for managing knowledge? Harvard Bus. Rev. 77(March-April) 106-116.

Heninger, W. G., A. R. Dennis, K. M. Hilmer. 2006. Individual cognition and dual-task interference in group support systems. Inform. Systems Res. 17(4) 415-424. 
Hilmer, K. M., A. R. Dennis. 2001. Stimulating thinking in decision making: Cultivating better decisions with groupware one individual at a time. J. Management Inform. Systems 17(3) 93-114.

Hiltz, R. S., K. Johnson. 1990. User satisfaction with computermediated communication systems. Management Sci. 36(6) 739-765.

Hogg, M. A., D. Abrams, S. Otten, S. Hinkle. 2004. The social identity perspective intergroup relations, self-conception, and small groups. Small Group Res. 35(3) 246-276.

Hollingshead, A. B. 1996. The rank-order effect in group decision making. Organ. Behav. Human Decision Processes 68(3) 181-193.

Hollingshead, A. B., J. E. McGrath, K. M. O'Connor. 1993. Group task performance and communication technology: A longitudinal study of computer-mediated versus face-to-face work groups. Small Group Res. 24 307-333.

$\mathrm{Hu}, \mathrm{J}$. 2003. Instant messaging corporate software vie for workplace. Retrieved March 25, 2007, CNET.com, http://news.cnet. com/Message+in+a+bottleneck/2009-1033_3-992348.html.

Huang, J. C., S. Newell. 2003. Knowledge integration process and dynamics within the context of cross-functional projects. Internat. J. Project Management 21(3) 167-176.

Ibarra, H. 1993. Personal networks of women and minorities in management: A conceptual framework. Acad. Management Rev. 18(1) 56-87.

Ickes, W., R. Gonzalez. 1994. Social cognition and social cognition: From the subjective to the intersubjective. Small Group Res. 25(2) 294-315.

Inkpen, A. C., E. W. Tsang. 2005. Social capital, networks, and knowledge transfer. Acad. Management Rev. 30(1) 146-165.

Jarvenpaa, S. L., K. Knoll, D. E. Leidner. 1998. Is anybody out there? The implications of trust in global virtual teams. J. Management Inform. Systems 14(4) 29-64.

Jarvis, C. B., S. B. Mackenzie, P. M. Podsakoff. 2003. Critical review of construct indicators and measurement model misspecification in marketing and consumer research. J. Consumer Res. 30 199-218.

Katz, N., D. Lazer, H. Arrow, N. Contractor. 2004. Network theory and small groups. Small Group Res. 35(3) 307-332.

Kiesler, S., J. Siegel, T. W. McGuire. 1984. Social psychological aspects of computer-mediated communication. Amer. Psychologist 39 1123-1134.

Kiesler, S., D. Zubrow, A. M. Moses. 1985. Affect in computermediated communication: An experiment in synchronous terminal-to-terminal discussion. Human-Comput. Interaction 1(1) 77-104.

Klein, K. J., S. W. J. Kozlowski. 2000. From micro to meso: Critical steps in conceptualizing and conducting multilevel research. Organ. Res. Methods 3 211-236.

Kostova, T., K. Roth. 2003. Social capital in multinational corporations and a micro-macro model of its formation. Acad. Management Rev. 28(2) 297-317.

Kramer, R. M., L. Goldman. 1995. Helping the group or helping yourself? Social motives and group identity in resource dilemmas. D. A. Schroeder, ed. Social Dilemmas. Praeger, Westport, CT, 49-67.

Kramer, R. M., M. Brewer, B. Hanna. 1996. Collective trust and collective action: The decision to trust as a social decision. R. M. Kramer, T. R. Tyler, eds. Trust in Organizations: Frontiers of Theory and Research. Sage Publications, Thousand Oaks, CA, 357-389.
Kwok, R., J. Ma, D. R. Vogel. 2002. Effects of group support systems and content facilitation on knowledge acquisition. J. Management Inform. Systems. 19(3) 185-229.

Lee, A. S. 1994. Electronic mail as a medium for rich communication: An empirical investigation using hermeneutic interpretation. MIS Quart. 18 143-157.

Leonard-Barton, D. 1995. Well-Springs of Knowledge. Harvard Business School Press, Boston.

Li, L. 2005. The effects of trust and shared vision on inward knowledge transfer in subsidiaries' intra- and inter-organizational relationships. Internat. Bus. Rev. 14(1) 77-95.

Lim, B. C., K. J. Klein. 2006. Team mental models and team performance: A field study of the effects of team mental model similarity and accuracy. J. Organ. Behavior 27 403-418.

Lin, B., C. Chen. 2006. Fostering product innovation in industry network: The mediating role of knowledge integration. Internat. J. Human Resources Management 17(1) 155-173.

Lin, N. 2001. Social Capital: A Theory of Social Structure and Action, Vol. 19. Cambridge University Press, New York.

Madhavan, R., R. Grover. 1998. From embedded knowledge to embodied knowledge: New product development as knowledge management. J. Marketing 62(4) 1-12.

Marks, M. A., M. J. Sabella, C. S. Burke, S. J. Zaccaro. 2002. The impact of cross-trainng on team effectiveness. J. Appl. Psych. 87(1) 3-13.

Mathieu, J., G. F. Goodwin, T. S. Heffner, E. Salas, J. A. CannonBowers. 2000. The influence of shared mental models on team process and performance. J. Appl. Psych. 85(2) 273-283.

Mathieu, J. E., T. S. Heffner, G. F. Goodwin, J. A. Cannon-Bowers, E. Salas. 2005. Scaling the quality of teammates' mental models: Equifinality and normative comparisons. J. Organ. Behav. 26(1) $37-56$.

Maznevski, M., K. Chuboda. 2000. Bridging space over time: Global virtual team dynamics and effectiveness. Organ. Sci. 11(5) 473-492.

McAllister, D. J. 1995. Affect- and cognition-based trust as foundations for interpersonal cooperation in organizations. Acad. Management J. 38(1) 24-59.

McGrath, J. E. 1984. Groups: Interaction and Performance. Prentice-Hall, Englewood Cliffs, NJ.

McGrath, J. E., A. B. Hollingshead. 1993. Putting the "group" back in group support systems: Some theoretical issues about dynamic processes in groups with technological enhancements. L. M. Jessup, J. E. Valacich, eds. Group Support Systems: New Perspectives. McMillan, New York, 78-96.

McLeod, P. L., R. S. Baron, M. W. Marti, K. Yoon. 1997. The eye have it: Minority influence in face-to-face and computer-mediated group discussion. J. Appl. Psych. 82(5) 706-718.

Mennecke, B. E., J. S. Valacich. 1998. Information is what you make of it: The influence of group history and computer support on information sharing, decision quality, and member perceptions. J. Management Inform. Systems 15(2) 173-197.

Nahapiet, J., S. Ghoshal. 1998. Social capital, intellectual capital, and the organizational advantage. Acad. Management Rev. 23(2) 242-266.

Neter, J., M. H. Kutner, C. J. Nachtsheim, W. Wasserman. 1996. Applied Linear Statistical Models, 4th ed. Irwin, Chicago.

Nunnally, J. 1978. Psychometric Theory, 2nd ed. McGraw-Hill, New York. 
Oh, H., M. Chung, G. Labianca. 2006. Group social capital and group effectiveness: The role of informal socializing ties. Acad. Management J. 47(6) 860-875.

Okhuysen, G. A., K. M. Eisenhardt. 2002. Integrating knowledge in groups: How formal interventions enable flexibility. Organ. Sci. 13(4) 370-386.

Olsen, S. 2002. IM giants told to work it out. Retrieved March 20, 2007, http://news.cnet.com/2100-1023-957787.html.

Patrashkova-Volzdoska, R. R., S. A. McComb, S. G. Green, W. D. Compton. 2003. Examining a curvilinear relationship between communication frequency and team performance in crossfunctional projects teams. IEEE Trans. Engrg. Management 50(3) 262-269.

Piccoli, G., B. Ives. 2003. Trust and the unintended effects of behavior control in virtual teams. MIS Quart. 27(3) 365-395.

Putnam, R. D. 2000. Bowling alone: The collapse and revival of American community. Simon and Schuster, New York.

Reagans, R. E., E. W. Zuckerman. 2001. Networks, diversity, and performance: The social capital of corporate R\&D units. Organ. Sci. 12(4) 502-517.

Reus, T., Y. Liu. 2004. Rhyme and reason: Emotional capability and the performance of knowledge-intensive work groups. Human Performance 17(2) 245-266.

Robert, L. P., A. R. Dennis. 2005. The paradox of richness: A cognitive model of media choice. IEEE Trans. Professional Comm. 48(1) 10-21.

Rulke, D. L., J. Galaskiewicz. 2000. Distribution of knowledge, group network structure, and group performance. Management Sci. 46(5) 612-626.

Scott, C. R. 1997. Identification with multiple targets in a geographically dispersed organization. Management Comm. Quart. 10(4) 491-522.

Shaw, M. 1964. Communication networks. L. Berkowitz, ed. Advances in Experimental Social Psychology. Academic Press, New York, 111-147.

Shaw, M. L. G. 2007. Interactive knowledge elicitation. Retrieved March 22, 2007, http://pages.cpsc.ucalgary.ca/ gaines/reports/ KBS/CIPS84M/index.html.

Shaw, M. L. G., C. McKnight. 1981. Think Again: Personal Decision Making and Problem Solving. Prentice Hall, Englewood Cliffs, NJ.

Shiu, E., A. Lenhart. 2004. How Americans use instant messaging, Pew Internet \& American Life Project, www.pewinternet. org/pdfs/PIP_Instantmessage_Report.pdf.

Shore, L. M., K. Barksdale. 1998. Examining degree of balance and level of obligation in the employment relationship: A social exchange approach. J. Organ. Behav. 19 731-744.

Siegel, J., V. Dubrovsky, S. Kiesler, T. W. McGuire. 1986. Group processes in computer mediated communication. Organ. Behav. Human Decision Processes 37 157-187.

Simons, T. L., R. S. Peterson. 2000. Task conflict and relationship conflict in top management teams: The pivotal role of intragroup trust. J. Appl. Psych. 85 102-111.

Sparrowe, R. T., R. C. Liden, S. J. Wayne, M. L. Kraimer. 2001. Social networks and the performance of individuals and groups. Acad. Management J. 44(2) 316-325.
Sproull, L., S. Kiesler. 1986. Reducing social context cues: Electronic mail in organizational communication. Management Sci. 32 1492-1512.

Stasser, G., D. D. Stewart. 1992. The discovery of hidden profiles by decision making groups: Solving a problem versus making a judgment. J. Personality Soc. Psych. 63 426-434.

Stasser, G., W. Titus. 1985. Pooling of unshared information in group decision making: Biased information sampling during discussion. J. Personality Soc. Psych. 48(6) 1467-1478.

Straus, S. G. 1996. Getting a clue: The effects of communication media and information distribution on participation and performance in computer-mediated and face-to-face groups. Small Group Res. 27(1) 115-142.

Straus, S. G., J. E. McGrath. 1994. Does the medium matter: The interaction of task type and technology on group performance and member reactions. J. Appl. Psych. 79(1) 87-97.

Strømsø, H. I., P. Grøttum, K. H. Lycke. 2007. Content and processes in problem-based learning: A comparison of computermediated and face-to-face communication. J. Comput. Assisted Learn. 23(3) 271-282.

Szulanski, G., R. Cappetta, R. J. Jensen. 2004. When and how trustworthiness matters: Knowledge transfer and the moderating effect of causal ambiguity. Organ. Sci. 15(5) 600-613.

Takahashi, N. 2000. The emergence of generalized exchange. Amer. J. Sociol. 105(4) 1105-1134.

Tiwana, A. 2004. Beyond the black box: Knowledge overlaps in software outsourcing. IEEE Software 21(5) 51-58.

Tiwana, A., E. R. McLean. 2005. Expertise integration and creativity in information systems development. J. Management Inform. Systems 22(1) 13-43.

Towry, K. L. 2003. Control in a teamwork environment-The impact of social ties on the effectiveness of mutual monitoring contracts. Accounting Rev. 78(4) 1069-1095.

Tsai, W., G. Ghoshal. 1998. Social capital and value creation: The role of intrafirm networks. Acad. Management J. 41(4) 464-476.

van der Kleij, R., R. Paashuis, J. M. Schraagen. 2005. On the passage of time: Temporal differences in video-mediated and face-toface interaction international. Internat. J. Human-Comput. Stud. 62(4) 521-542.

Vroom, V. H., P. W. Yetton. 1973. Leadership and Decision-Making. University of Pittsburgh Press, Pittsburgh.

Wasko, M. M., S. Faraj. 2005. Why should I share? Examining social capital and knowledge contribution in electronic networks of practice. MIS Quart. 29(1) 35-57.

Wichman, H. 1970. Effects of isolation and communication on cooperation in a two-person game. J. Personality Soc. Psych. 16 114-120.

Wittenbaum, G. M., A. B. Hollingshead, P. B. Paulus, R. Y. Hirokawa, D. G. Ancona, R. S. Peterson, K. A. Jehn, K. Yoon. 2004. The functional perspective as a lens for understanding groups. Small Group Res. 35(1) 17-43.

Yamagishi, T., K. S. Cook. 1993. Generalized exchange and social dilemmas. Soc. Psych. Quart. 56(4) 235-248.

Zack, M. H., McKenney, J. L. 1995. Social context and interaction in ongoing computer-supported management groups. Organ. Sci. 6(4) 394-422. 
Copyright 2008, by INFORMS, all rights reserved. Copyright of Information Systems Research is the property of INFORMS: Institute for Operations Research and its content may not be copied or emailed to multiple sites or posted to a listserv without the copyright holder's express written permission. However, users may print, download, or email articles for individual use. 